\section{Hillary and Donald, Our Patients Are Watching}

The United States of America has never seen anything like it. This presidential race is, well, unusual. And that's an understatement for sure! I don't think politics belongs in this column, so I won't go there (although secretly I want too!). But after listening to the candidates, I began to wonder what our patients are thinking. The candidates emphasize taking down terrorists (I get that), tax reform, fixing whatever is broken (not too many specifics there), protecting and improving the lives of children, and on and on. But I've heard very little about healthcare and even less about cancer care.

Historically, of course, the Republicans have wanted to repeal the Affordable Care Act (ACA), but that doesn't seem likely. Even though it's not perfect, and many things could be improved, many Americans have benefitted from this legislation. Americans have more affordable choices, can get insurance even if they have preexisting conditions, and can more easily change plans as their needs change.

But hearing more specifics on healthcare reform in the presidential platforms would be refreshing. At least we would know healthcare was on their radar. Legitimate concerns exist about whether the ACA implementation has affected access to highquality care. For example, is your plan so narrow that you can't get the specialized care you need? Or did you get locked into a tiered formulary that calls for higher out-of-pocket costs on certain drugs? We need some way to monitor this so we can understand how the changes have affected our patients. That's the only way we will know what to fix.

And what about MACRA (Medicare Access \& CHIP Reauthorization Act of 2015)? It's not fully implemented yet, but it's coming. It promises reimbursement reform, quality improvement and measurement, and public transparency. This all sounds good, but the devil is in the details, right? Reimbursement reform, if not done well, could further cripple community practices. Lately, we've seen one experiment after another coming from CMS. Can we please get some results first, and then put order into this process so we really know how these changes affect our ability to deliver the care our patients deserve?

The quality care part of MACRA is particularly concerning. We will all need to fill out a lot of reports to demonstrate our ability to provide high-quality care. It's going to cost a lot, so we should do it right. But how do we know we have the right metrics? How do we know whatever we measure will improve decision-making? And who will pay for this?

Of course, neither the ACA nor MACRA addresses the problems of the high cost of drugs (can't someone fix this?), the need for more resources for federal agencies that fund biomedical research, and the limitations placed on physician and patient communication by HIPAA and by existing electronic health records systems that can't interface with each other.

As the presidential debates proceed, I hope some of these issues will get some air time. And I hope America has the good sense to elect a President willing to work on a bipartisan approach to healthcare reform. You need to help, too. Start by voting!

What do you think? Please e-mail correspondence (include contact information) to JNCCN@nccn.org.

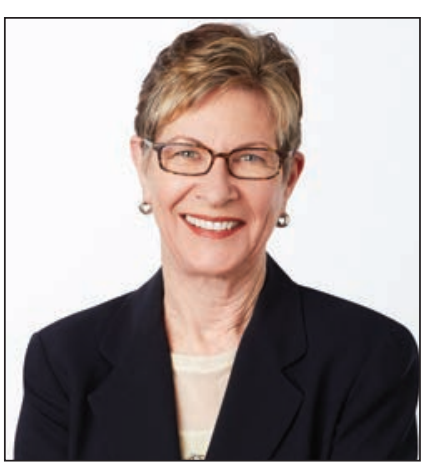

Margaret Tempero, MD

Margaret Tempero, MD, is a Professor of Medicine and Director of the UCSF Pancreas Center and editor-in-chief of JNCCN. Her research career has focused on pancreatic ductal adenocarcinoma, especially in the area of investigational therapeutics. Dr. Tempero has served on the ASCO Board of Directors and as ASCO President. She currently serves on the ASCO Conquer Cancer Foundation Board. She codirected the AACR/ASCO Methods in Clinical Cancer Research and taught this course and similar courses in Europe and Australia. She was founding Chair of the $\mathrm{NCl}$ Clinical Oncology Study Section and served as a member and Chair of the NCl Board of Scientific Counselors Subcommittee $A$. She is a member of the Scientific Steering Committee and Chair of the Clinical and Translational Study Section for the Cancer Prevention \& Research Institute of Texas. She is or has been on the Scientific Advisory Boards of the Lustgarten Foundation, the Pancreatic Cancer Action Network, the $V$ Foundation, The Alberta Canada Cancer Board, and the EORTC. She served as a member of the Oncology Drug Advisory Committee for the FDA. She has served as Deputy Director and Interim Director for the UNMC Eppley Cancer Center. She is Chief Emeritus of the Division of Medical Oncology at UCSF and served as the founding Deputy Director and Director of Research Programs at the UCSF Helen Diller Family Comprehensive Cancer Center.

The ideas and viewpoints expressed in this editorial are those of the author and do not necessarily represent any policy, position, or program of NCCN. 